\title{
EL USO DE TÚ Y USTED EN EL ÁREA METROPOLITANA DE VALENCIA. UN ENFOQUE VARIACIONISTA
}

\author{
THE USE OF TÚ Y USTED IN THE METROPOLITAN AREA OF VALENCIA. A \\ VARIATIONIST APPROACH
}

\author{
JoRge Roselló Verdeguer \\ Universitat de València \\ Jorge.Rosello@uv.es
}

Recibido: $23 / 08 / 2017$

Aceptado: 03/10/2017

\begin{abstract}
Resumen
En este trabajo se realiza un estudio estadístico sobre el uso de las formas de tratamiento en Valencia y su área metropolitana. Tras una breve introducción teórica sobre el tema y la explicación de la metodología utilizada, ofrecemos los resultados en términos porcentuales. Pero, al tratarse de un fenómeno en el que intervienen múltiples factores al mismo tiempo, hemos realizado también un análisis de regresión, que permite ver los resultados cuando todos los factores actúan de manera simultánea. Todas las variables que hemos analizado, salvo la lengua habitual (castellano o valenciano), resultan estadísticamente significativas, si bien las probabilidades de aparición del tuteo son muy altas en el ambiente familiar, sobre todo el más próximo (hijos, hermanos y pareja) y en personas de menor edad al interlocutor. Sin embargo el tuteo se ve frenado por la mayor edad del interlocutor o cuando no existe ningún vínculo entre las personas.

PALABRAS CLAVE: pronombres de tratamiento, tú, usted, sociolingüística variacionista, análisis de regresión.
\end{abstract}

\begin{abstract}
This paper is a statistical study of the use of form of address in Valencia and its metropolitan area. After a brief theoretical introduction on the subject and the explanation of the methodology used, we offer the results as percentages. However, since it is a phenomenon involving multiple factors at the same time, we have also performed a regression analysis, which allows us to see the results when all the factors act simultaneously. All variables that we analyzed, except for the usual language (Spanish or Valencian) are statistically significant, but the probabilities of occurence of the tuteo are very high in the family environment, especially the closest one (children, siblings and couples) and in people who are younger than the interlocutor. But the tuteo does not occur with people who are older than interlocutor or when there is no link between them.

KEYWORDS: address pronouns, tú, usted, variationist sociolinguistics, regression analysis.
\end{abstract}

Para citar este artículo / To cite this article: Roselló Verdeguer, Jorge (2017). El uso de tú y usted en el área metropolitana de Valencia. Un enfoque variacionista. ELUA, 31: 285-309. doi: 10.14198/ ELUA2017.31.15

Enlace / Link: http://dx.doi.org/10.14198/ELUA2017.31.15 


\section{INTRODUCCIÓN}

Las formas de tratamiento han merecido la atención de numerosos gramáticos y lingüistas, que han analizado desde diferentes puntos de vista las causas que originan las diversas maneras de dirigirse al interlocutor. En la elección de la variante pronominal, como recuerdan muchos estudiosos del tema, intervienen numerosos factores, entre los que cabe destacar la confianza, la cercanía o el grado de formalidad existente entre los interlocutores. Pero la lista no termina, por supuesto, ahí. De hecho, los factores irán variando dependiendo del enfoque que se le quiera dar al tema. Como recuerda Blas Arroyo (2005: 298), si adoptamos un enfoque variacionista, serán los factores sociales y contextuales los que adquieran mayor importancia; pero también es posible considerar estas formas de tratamiento como manifestaciones diferentes de un principio básico del análisis conversacional, como es la cortesía lingüística. De igual modo, podemos considerar estos pronombres como indicios de contextualización, en cuyo caso estaremos poniendo el foco en las estrategias discursivas llevadas a cabo por los interlocutores para la consecución de ciertos objetivos.

Gran parte de los estudios sociolingüísticos de los tratamientos en español toman como punto de partida el conocido trabajo de Brown y Gilman (1960) sobre los conceptos de poder y solidaridad, y participan de las ideas básicas formuladas por estos autores, que señalaron, por un lado, la tendencia a la supresión del eje semántico del poder en favor de la solidaridad, lo que ha provocado una disminución del tratamiento asimétrico y, paralelamente, un aumento del simétrico; y, por otro, la constatación de que el ámbito de la solidaridad informal, es decir, el tuteo mutuo, se ha extendido considerablemente.

El trabajo que presentamos aquí es un estudio estadístico de carácter inferencial sobre uso de las formas pronominales en Valencia y su área metropolitana. En un estudio anterior (Roselló 2013), realizamos un análisis bivariante, que nos permitió conocer cuantitativamente la frecuencia y la distribución de la variable dependiente (en este caso las formas de tratamiento tú y usted) en relación con cada una de las variables independientes consideradas, que eran, por un lado, los diversos interlocutores a los que había que dirigirse (padre, madre, hermanos, abuelos, vecinos, conocidos, jefes, camareros...) y, por otro, las variables habituales con las que trabaja la sociolingüística variacionista: edad, sexo, nivel de estudios $\mathrm{y}$, en nuestro caso, al ser un territorio bilingüe, la lengua habitual de comunicación. Sin embargo, con este tipo de análisis, solo podíamos poner en relación la variable dependiente con una variable independiente cada vez, pero no con todas al mismo tiempo. Esto solo es posible con un análisis multivariante, el cual permite mostrar la incidencia combinada de todas las variables independientes actuando conjuntamente.

Por tanto, lo que aquí proponemos es completar aquel trabajo realizando ahora un análisis multivariante con el que se podrá combinar la interacción de todos los factores que intervienen en el proceso para conocer cuál es la jerarquía entre ellos. Este tipo de análisis nos indicará cuál es la posibilidad de que se seleccione una de las dos variantes (tú o usted) cuando actúan de forma combinada todas las variables independientes que hemos seleccionado (interlocutor, edad, sexo, grado de instrucción y lengua habitual del informante).

Para ello hemos utilizado el programa Goldvarb X, heredero de una larga tradición de programas informáticos diseñados específicamente para el cálculo de la regresión logística binomial, y que representa una de las pocas opciones disponibles de análisis estadístico 
específico para la regla variable en la investigación variacionista ${ }^{1}$. Se trata, en palabras de Buzón García (2013: 22), de un "programa informático que implementa un algoritmo iterativo con el que se produce el cálculo de la fórmula de regresión logística binomial clásica diseñado particularmente para su uso en la investigación variacionista". Este programa fue desarrollado por David Sankoff, en colaboración con H. Cedergren, W. Labov y P. Rousseau, y pretendía facilitar la manipulación de los datos procedentes de estudios lingüísticos y ayudar a los investigadores en la correcta interpretación de los análisis de regresión logística.

Comenzaremos el artículo refiriéndonos al marco teórico. No es nuestro propósito realizar aquí una panorámica de todos los estudios realizados sobre las formas pronominales en el mundo hispánico. En primer lugar porque nos circunscribimos al uso de tú y usted en Valencia, que correspondería al sistema II del que habla Fontanella de Weinberg (1999: 1402), extendido por toda la península ibérica, salvo en las zonas de Andalucía. Y, en segundo lugar, porque el marco teórico en el que se inscriben las fórmulas de tratamiento dispone ya de una extensa bibliografía a la que el lector puede acudir para profundizar en sus conocimientos ${ }^{2}$. En lugar de ello, hemos preferido referirnos tan solo a los estudios, a nuestro juicio, más significativos e ilustrarlos con artículos de prensa y anuncios publicitarios. Tras el marco teórico, explicamos la metodología utilizada, basada en la encuesta elaborada por el equipo PRESEEA, y la utilización del programa Goldvarb X para el estudio estadístico. Realizamos, a continuación, el estudio cuantitativo, tanto de frecuencias y porcentajes como el análisis de regresión logística, y acabamos con unas breves conclusiones.

\section{MARCO TEÓRICO}

En un reciente artículo de prensa, el escritor y académico Javier Marías decía lo siguiente:

Me escribe un señor de setenta y cinco años, desesperado porque las instituciones financieras recurran invariablemente al tuteo para dirigirse a sus clientes. Cuenta que las cartas de su banco empiezan con "un desenfadado 'Hola"” y siguen con "un irrespetuoso tuteo". Cuando el contacto es telefónico, ocurre lo mismo, y si el señor les afea las excesivas confianzas, los empleados le responden que ellos "solo obedecen instrucciones". De poco le sirve a don Ezequiel advertirles de que, si persisten en lo que para él es una grosería, retirará sus fondos. Y se pregunta: “¿Cuál será el siguiente paso, tratarme de 'tronco', 'tío' o 'colega'?” [...] Y francamente, si los bancos - nada menos - dan instrucciones de tutear a todo el mundo; si lo hacen obligatorio como en los hospitales y las Universidades y en demasiados sitios "respetables", hay que concluir que también ese tuteo impostado forma ya parte de lo más institucional, reaccionario y rancio ${ }^{3}$.

No cabe duda de que el tuteo se ha extendido considerablemente durante los últimos años. Este fenómeno no ha pasado inadvertido a los lingüistas que han estudiado el uso de los pronombres tú y usted, ni, en general, a muchos ciudadanos, que -como en el caso de

1 Hoy en día existen otros programas alternativos a Goldvarb. Destacan Rbrul, una extensión de la Plataforma $R^{7}$, y el programa SPSS, muy usado por las ciencias sociales y por empresas de investigación de mercado, y que también permite realizar cálculos de regresión logística binomial.

2 Toda la bibliografía al respecto puede consultarse en Fernández, F. y K. Gerhalter (2017).

3 Artículo publicado en El País Semanal, n. ${ }^{\circ} 2.122$ (28 de mayo de 2017). 
la persona a la que se refiere Javier Marías- no ven muy adecuado el tratamiento que se le dispensa. Como ya hemos dicho, Brown y Gilman (1960), en un trabajo que se considera pionero en los estudios de tratamiento, advirtieron ese cambio de tendencia y el uso cada vez más frecuente del tuteo.

En España, la mayor parte de los estudios sobre formas de tratamiento se ha efectuado siguiendo las directrices de Brown y Gilman y, en líneas generales, ha elegido grupos jóvenes de población y sociedades de carácter urbano. Así, el trabajo de Borrego Nieto, Gómez Asencio y Pérez Bowie (1978) se centra en estudiantes universitarios de Salamanca y considera la edad el factor fundamental en la extensión del tuteo. En el estudio de Alba de Diego y Sánchez Lobato (1980), realizado en un instituto de Bachillerato de Madrid, se confirma el predominio de un sistema de relaciones simétricas en el tratamiento pronominal. Una década más tarde, Molina Martos (1993), tomando también como informantes a estudiantes universitarios, reafirma el dominio casi total de estas relaciones simétricas. Como ponen de manifiesto Calderón Campos y Medina Morales (2010: 202), todas estas investigaciones realizadas en España coinciden en la existencia de dos tendencias: en primer lugar, el aumento de tú a expensas de usted, especialmente en los grupos más jóvenes, en las relaciones de afecto en las que hay jerarquía (familia / ámbito educativo) e incluso se dan cuando hay ausencia de conocimiento, sobre todo si el destinatario pertenece al mismo segmento de edad, aunque usted sigue siendo mayoritario entre desconocidos. En segundo lugar, en las relaciones jerárquicas hay una marcada preferencia por el trato simétrico formal (uso de usted en las dos direcciones). De igual modo, hay importantes diferencias entre los distintos grupos de edad, ya que las personas mayores prefieren usted en mayor medida cuando no hay familiaridad.

Como decimos, la edad es el factor fundamental para el análisis de la distribución sociolingüística de las formas de tratamiento. Así, la generalización de tú avanza sobre todo en las generaciones más jóvenes. Esto se puede observar en la publicidad y en los anuncios de prensa, en los que se tiene muy en cuenta la edad del interlocutor. Así, podemos observar el uso de usted (Figura 1) al dirigirse a un supuesto cliente afectado por las llamadas "acciones preferentes", ya que, seguramente, el anunciante supuso que gran parte de las víctimas de estas acciones de la banca eran personas mayores. Sin embargo, cuando se descubrió que entre los supuestos estafados también había personas jóvenes (en este caso, el jugador de fútbol Iker Casillas), se cambió la forma de tratamiento (Figura 2).

Sin embargo, en la línea marcada por el protagonista del artículo de Javier Marías, el tuteo, en el mundo de la publicidad y del márquetin, también se extiende a las personas mayores, como se ve en la Figura 3. Tal vez de lo que se trata aquí es de lo que SolerEspiauba (1994) denominaba como tuteo de "seducción comercial", que tendría un objetivo psicológico de atraer al cliente para crear un clima adecuado que le anime, en este caso, a reclamar sus derechos.

Molina Martos (2005: 114), en un interesante trabajo sobre la evolución de las formas de tratamiento, demuestra que se ha producido un verdadero cambio lingüístico, todavía en marcha, que se irradia a través de la generación más joven, que es el grupo difusor del tuteo y de otras formas nominales innovadoras, y que se extiende al resto de los niveles generacionales. Pero, además, ese cambio en las formas de tratamiento se ha convertido en un cambio comunitario, porque afecta en mayor o menor medida a todas las generaciones de la comunidad, de forma regular y a lo largo del tiempo. En líneas generales, en un estudio 


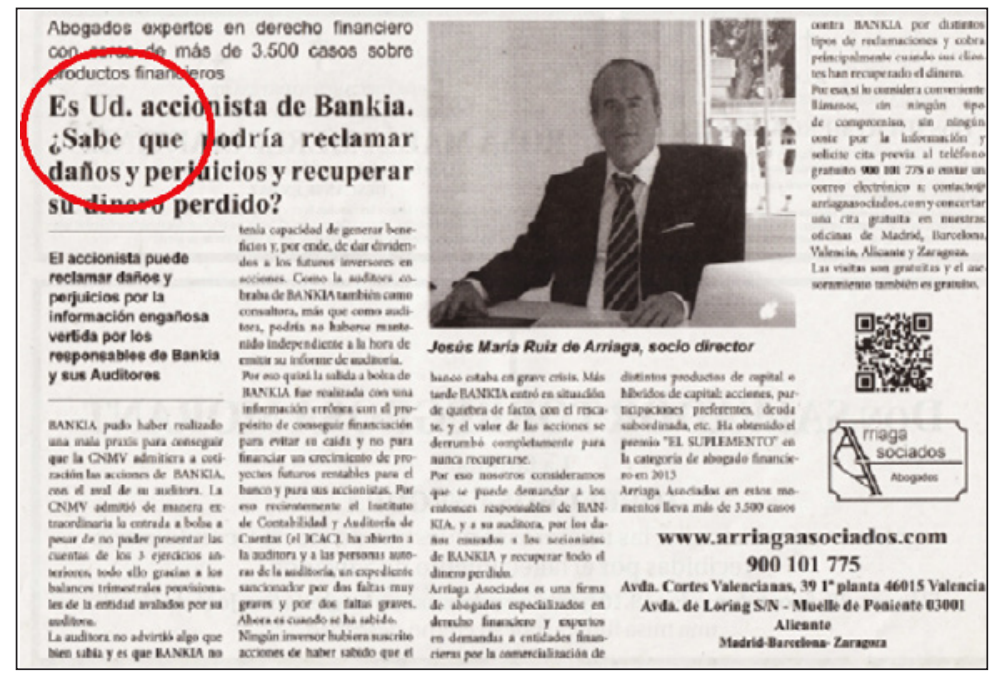

Figura 1

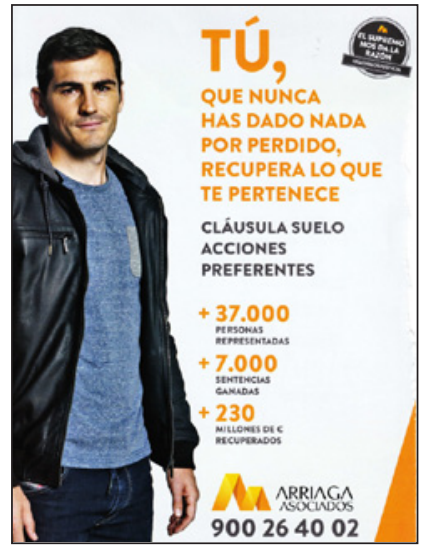

Figura 2

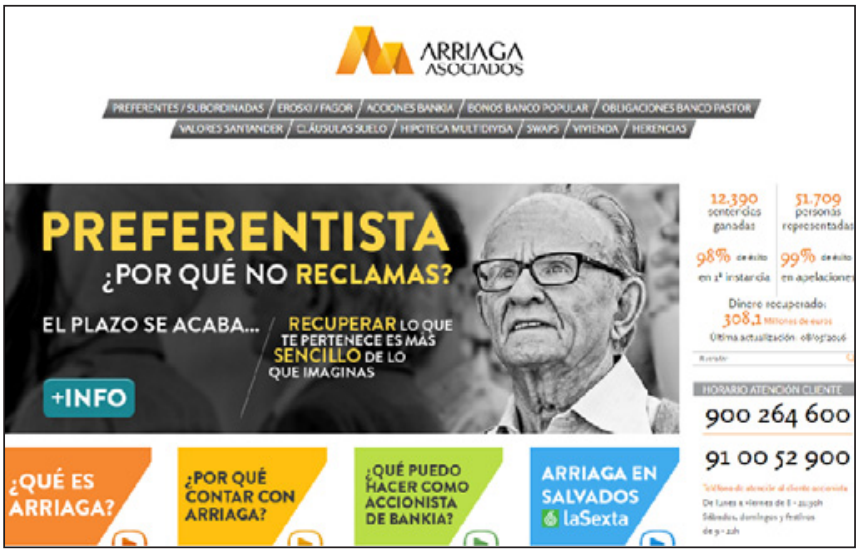

Figura 3

realizado en Valencia, constatamos (Roselló 2013) que los encuestados preferían el tuteo, ya que, ante la pregunta de cómo le gusta que lo/la traten, la gran mayoría de encuestados (un $86,1 \%$ ) prefieren ser tratados de tú. Es lo que se refleja, por ejemplo, en la mayoría de los medios de comunicación a la hora de dirigirse a sus lectores (Figura 4).

También se ha vinculado el empleo de tú y usted con el fenómeno de la cortesía, aspecto introducido en este contexto a partir de los trabajos de Brown y Levinson (1987). Desde esta perspectiva, se considera que las formas de tratamiento son expresiones referenciales que emplea el hablante para dirigirse al destinatario y pertenecen al ámbito de la deixis social, ya que codifican la identidad de los participantes y la relación entre ellos, es decir, cumplen una función fundamental en la manifestación de dicha cortesía. De este modo, se reservaría 
el carácter cortés a la forma usted, mientras que tú se asociaría a otros parámetros (familiaridad, confianza, solidaridad, etc.). Como pone de manifiesto Iglesias Recuero (2001: 256), los hablantes reconocen la existencia de normas sociales que sancionan el uso de las distintas formas de tratamiento, y la cortesía, entendida como comportamiento adecuado a la situación, incluye la selección del tratamiento adecuado o esperable. Es el caso del titular seleccionado en la Figura 5, "Hemos pasado de ser invisibles a que nos traten de usted", en donde se pasa del ninguneo que supone no tener consideración alguna, a la forma máxima de respecto, representada por el tratamiento de usted.

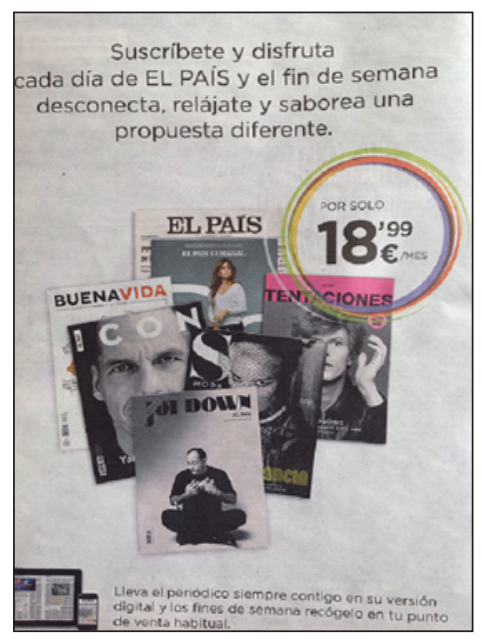

Figura 4

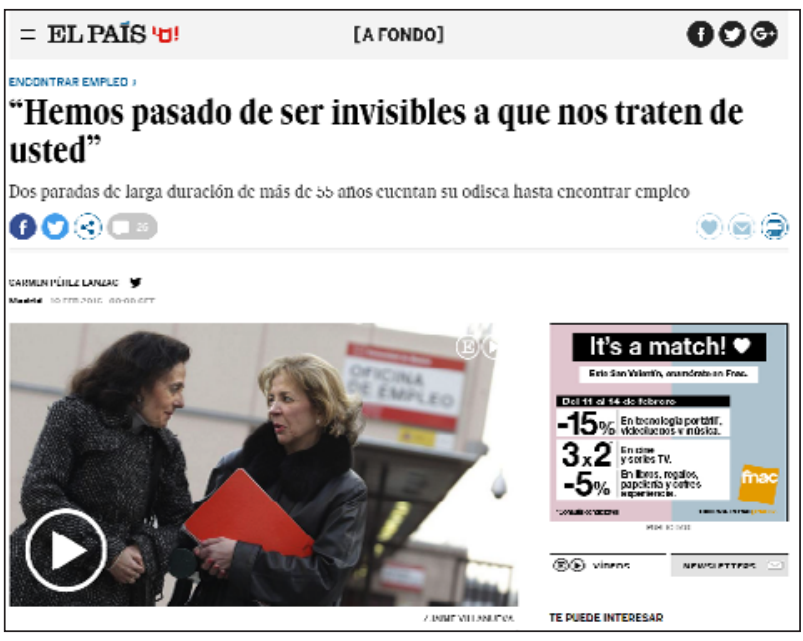

Figura 5

Si bien, como se ha dicho, el tuteo no ha hecho más que extenderse en los últimos años, es difícil imaginarse una generalización de esta forma de tratamiento, una "muerte del usted", que auguraba Dámaso Alonso en un célebre artículo ${ }^{4}$. Por ello, concluimos este apartado con otra cita, esta vez del también escritor y académico Arturo Pérez Reverte, que, al ser increpado de forma no muy educada por un guardia (¿Qué pasa? ¿No has visto el semáforo o qué?), tras cometer una infracción de tráfico, le dijo al agente: Tiene usted razón, pero ¿por qué me tutea? Acto seguido, cuenta el escritor, el policía pasó al usted y tuvo los reflejos de responder: No oigo lo que me dice, señor; siga adelante y no se quede en ese lugar 5 .

\section{METODOLOGÍA}

Para la realización de este estudio hemos aplicado la encuesta elaborada por los miembros del equipo PRESEEA (Proyecto para el Estudio Sociolingüístico del Español

4 "La muerte del usted", artículo publicado en el diario $A B C$ (23 de noviembre de 1947).

5 Artículo publicado en XL Semanal (26 de mayo de 2013). 
de España y América). En las bases metodológicas de dicho proyecto, se establece que su finalidad principal es contar con unos materiales básicos para facilitar la comparación de los estudios realizados, de ahí que los diversos equipos que forman parte del proyecto utilicen los mismos materiales. Para este trabajo, hemos seleccionado la propuesta del equipo de Barcelona, incluida en la metodología del grupo ${ }^{6}$.

Los cuestionarios, como han puesto de relieve algunos investigadores, son un método limitado y no siempre aportan toda la información necesaria. En este sentido, Michele de Oliveira (2010) señala que los cuestionarios no dejan espacio para señalar factores determinantes adicionales. Así, por ejemplo, podemos ver qué fórmula de tratamiento elige el informante al dirigirse a un interlocutor (vecino, camarero, profesor, médico...), pero no se nos informa sobre cuáles son los factores determinantes para elegir la forma pronominal, como pueden ser el grado de confianza o de intimidad que se tenga con él, la frecuencia de contacto, la posición social, el nivel de educación, etc. Todas estas cuestiones pueden influir en la elección del pronombre y es posible, igualmente, que al contestar, el informante tenga en su mente un cierto "vecino" o "camarero" al responder el cuestionario.

Con todo, son también muchas las ventajas que ofrece la utilización del cuestionario. Como indica Paredes (2010: 186), un cuestionario es un instrumento que en última instancia ha de servir para evaluar el estado en que se encuentra un determinado hecho social $y$, por ello, es una herramienta de evaluación que implica que ha de cumplir los requisitos para este tipo de instrumentos: validez, fiabilidad y visibilidad. Además, contar con una propuesta susceptible de aplicarse en diferentes comunidades de habla otorga la ventaja de poder comparar los resultados obtenidos a partir de condiciones y circunstancias semejantes y equiparables. Por otro lado, los datos extraídos permiten comparar los resultados con otros trabajos similares y comprobar si las tendencias se mantienen o han evolucionado a lo largo del tiempo. Es el estudio que llevó a cabo, por ejemplo, Molina Martos (2005), que realizó una investigación sobre las fórmulas de tratamiento en jóvenes de Madrid en dos momentos distintos (1988 y 2000), mediante un cuestionario cerrado que le permitió la comparación de datos de manera sistemática.

El cuestionario que hemos utilizado se divide en tres apartados: I. Fórmulas de tratamiento pronominal, en el que se incluyen preguntas sobre la forma usada y sobre las actitudes; II. Fórmulas de tratamiento nominales empleadas con diferentes interlocutores (familia, amigos, pareja y conocidos); y III. Fórmulas rituales: saludos de paso, despedidas, respuestas cortas a preguntas y petición de servicios. Para este trabajo, nosotros solo hemos utilizado el apartado I (fórmulas de tratamiento pronominal), ya que son preguntas cerradas que se adecuan mejor al estudio estadístico que aquí realizamos. El cuestionario que se pasó a los informantes es el que aparece a continuación.

\footnotetext{
6 Para saber más sobre los objetivos, metodología, equipos, etc. de PRESEEA, puede consultarse la página electrónica del grupo (www.preeea.linguas.net), así como los trabajos de Moreno Fernández (1996, 2005) y Cestero Mancera (2013).
} 


\section{FORMAS DE TRATAMIENTO PRONOMINAL}

1. Formas de tratamiento empleadas con los siguientes interlocutores:

\begin{tabular}{|l|l|l|l|}
\hline INTERLOCUTOR & TÚ & USTED & TÉRMINO EN OTRO IDIOMA \\
\hline Padre & & & \\
\hline Madre & & & \\
\hline Hijos & & & \\
\hline Hermanos & & & \\
\hline Pareja & & & \\
\hline Suegro & & & \\
\hline Suegra & & & \\
\hline Abuelos paternos & & & \\
\hline Abuelos maternos & & & \\
\hline Amigos & & & \\
\hline Vecinos & & & \\
\hline Otros conocidos & & & \\
\hline Desconocidos & & & \\
\hline Médico & & & \\
\hline Profesor & & & \\
\hline Jefe & & & \\
\hline Sacerdote & & & \\
\hline Servicio doméstico & & & \\
\hline Camarero & & & \\
\hline Conductor de Autobús / taxi & & & \\
\hline
\end{tabular}

Comentarios:

\section{Aspectos sociales}

Escribir la forma de tratamiento utilizada (TÚ, USTED) en los siguientes casos.

\begin{tabular}{|l|c|l|l|}
\hline \multicolumn{1}{|c|}{ SEXO } & & Hombre & Mujer \\
\hline \multirow{4}{*}{ EDAD } & Mayor que yo & & \\
\cline { 2 - 4 } & Igual que yo & & \\
\hline & Menor que yo & & \\
\hline \multirow{3}{*}{ ESTRATO SOCIAL } & Superior al mío & & \\
\cline { 2 - 4 } & Igual al mío & & \\
\hline & Inferior al mío & & \\
\hline
\end{tabular}


Además, se preguntaban los siguientes datos al informante:

Sexo: _ $\mathrm{H} \_\mathrm{M}$

Edad: ...... años

Lugar de nacimiento:

Provincia:

Lugar actual de residencia:

Si no ha vivido allí siempre, indique desde cuándo (año):

Nivel de estudios:

Profesión:

Renta familiar anual:

Escala socioeconómica subjetiva: __Alta o Media-alta __ Media __Media-baja_Baja

Lengua materna:

Lengua habitual:

Para nuestro estudio, realizado en la comunidad de habla bilingüe de Valencia y su área metropolitana ${ }^{7}$, han sido 115 informantes quienes han cumplimentado el cuestionario. En la Tabla 1 se muestra la distribución de los informantes en cada uno de los estratos sociológicos establecidos: edad (20-34 años, 35-55 años y mayor de 55 años), nivel de estudios (primarios, secundarios y universitarios), sexo (hombre y mujer) y lengua habitual (castellano-hablante y bilingüe activo) ${ }^{8}$.

\begin{tabular}{|c|c|c|c|c|c|c|c|c|}
\hline \multirow{2}{*}{ Edad } & \multicolumn{6}{|c|}{ Grado de instrucción } & \multirow{2}{*}{\multicolumn{2}{|c|}{ TOTAL }} \\
\hline & \multicolumn{2}{|c|}{ Primarios } & \multicolumn{2}{|c|}{ Secundarios } & \multicolumn{2}{|c|}{ Universitarios } & & \\
\hline 20-34 años & $\begin{array}{l}\text { Н } 6, \text { M } 5 \\
\text { C } 6, \text { B } 5\end{array}$ & 11 & $\begin{array}{l}\text { H 7, M } 7 \\
\text { C 7, B } 7\end{array}$ & 14 & $\begin{array}{l}\text { Н } 6, \text { M } 6 \\
\text { C } 7, \text { B } 5\end{array}$ & 12 & $\begin{array}{l}\text { H } 19, \text { M } 18 \\
\text { C } 20, \text { B } 17\end{array}$ & 37 \\
\hline 35-55 años & $\begin{array}{l}\text { Н 6, M } 6 \\
\text { C 5, В } 7\end{array}$ & 12 & $\begin{array}{l}\text { H 6, M } 7 \\
\text { C 8, B } 5\end{array}$ & 13 & $\begin{array}{l}\text { H 9, M } 5 \\
\text { C } 6, \text { B } 8\end{array}$ & 14 & $\begin{array}{l}\text { H 21, M } 18 \\
\text { C } 19, \text { B } 20\end{array}$ & 39 \\
\hline$>55$ años & $\begin{array}{l}\text { H 6, M } 8 \\
\text { C 7, B } 7\end{array}$ & 14 & $\begin{array}{l}\text { H 7, M } 5 \\
\text { C 5, B } 7\end{array}$ & 12 & $\begin{array}{l}\text { H 7, M } 6 \\
\text { C } 8 \text {, B } 5\end{array}$ & 13 & $\begin{array}{l}\text { H 20, M } 19 \\
\text { C 20, В } 19\end{array}$ & 39 \\
\hline TOTAL & $\begin{array}{l}\text { H } 18, \text { M } 19 \\
\text { C } 18, \text { B } 19\end{array}$ & 37 & $\begin{array}{l}\text { Н } 20, \text { М } 19 \\
\text { С } 20, \text { В } 19\end{array}$ & 39 & $\begin{array}{l}\text { Н } 22, \text { M } 1 \\
\text { C } 21, \text { B } 18\end{array}$ & 39 & $\begin{array}{l}\text { H } 60, \text { M } 55 \\
\text { C } 59, \text { B } 56\end{array}$ & 115 \\
\hline
\end{tabular}

Tabla 1. Distribución de los informantes en cada uno de los estratos sociológicos establecidos.

7 Se entiende por área metropolitana (Jordá 1986: 676) "un conjunto geográfico donde hay una serie de interacciones económicas y sociales en uno o varios núcleos importantes, ligados por una trama viaria, de información y de todo tipo de corrientes de distintos sentidos". El área metropolitana de Valencia está integrada por cuarenta y cuatro municipios y tiene una población de 1.534.557 habitantes (según los datos del Padrón de 2014).

8 Es un territorio donde se habla, además de castellano, valenciano, denominación que tradicional y popularmente recibe la lengua catalana hablada en la Comunidad Valenciana (Casanova 2003: 117). 
La variable lingüística es la unidad fundamental de estudio de la sociolingüística variacionista. Moreno Fernández (2005: 21) la define como "un conjunto de expresiones de un mismo elemento", a la vez que concibe las variantes como "cada una de las manifestaciones o expresiones de una variable". La definición de variable lingüística incluye necesariamente el establecimiento de un conjunto limitado y cerrado de datos a los que se puede aplicar el axioma de la teoría probabilística.

Por otra parte, la variable lingüística constituye la unidad de análisis de la llamada "regla variable", que surge como necesidad de superar los planteamientos generativistas de la competencia lingüística con el fin de incluir la posibilidad de una variación sistemática en la lengua. La regla variable exige la configuración de una metodología específica basada en el establecimiento de una variable lingüística definida y apta para la aplicación de axiomas probabilísticos, y una selección de variables independientes o grupos de factores que podrían estar condicionando la variación. Para su cálculo se aplican unos instrumentos estadísticos, tanto descriptivos como inferenciales y predictivos para su cuantificación. Estos últimos otorgan al análisis de la regla variable un mayor poder explicativo que trasciende la mera descripción superficial de los fenómenos, puesto que, a partir de ellos, se pueden realizar estimaciones y predicciones acerca del proceso de cambio lingüístico promovidos por la variación (Buzón García 2013: 41).

El variacionismo ha contado desde el principio con programas informáticos que han contribuido al cálculo de la fórmula de regresión logística de máxima verosimilitud, que ha sido el modelo de análisis de la regla variable. Los programas más utilizados para el análisis de estos datos lingüísticos han sido los programas Varbrul y, posteriormente, Goldvarb, cuyo nacimiento se debió a la colaboración entre una lingüista, Henrietta Cedergren, y un matemático, David Sankoff, con las directrices aportadas por William Labov. El que hemos utilizado aquí, Goldvarb X, fue desarrollado por Sankoff, Tagliamonte y Smith (2005).

La variable dependiente o lingüística es, en este caso, la forma pronominal de tratamiento, con dos variantes: tú y usted. Las variables dependientes o grupos de factores que se han seleccionado son:

a) Interlocutores, que hemos dividido en varios subapartados:

a. Ámbito I (la familia): padre, madre, hijos, hermanos, pareja, suegro, suegra, abuelo paterno, abuelo materno.

b. Ámbito II (relaciones sociales): amigos, vecinos, conocidos, desconocidos.

c. Ámbito III (mundo laboral): médico, profesor, jefe, sacerdote, servicio doméstico, camarero, conductor de taxi o autobús.

d. Edad del interlocutor: mayor que el informante, igual que el informante o menor que el informante.

e. Estrato social: superior al informante, igual al del informante, inferior al del informante.

b) Edad del informante: 20-25 años, 35-55 años, mayores de 55 años.

c) Nivel de estudios del informante: primarios, secundarios y universitarios.

d) Sexo del informante: hombre, mujer.

e) Lengua habitual del informante: castellano-hablante, bilingüe activo. 


\section{ANÁLISIS Y RESULTADOS}

\subsection{Estudio cuantitativo: frecuencias y porcentajes}

Lo primero que nos ofrece el programa Goldvarb $X$ es un recuento de las frecuencias y los porcentajes de las formas tú y usted $^{9}$ en cada una de las variables analizadas (Figura 6).

\begin{tabular}{llcccc}
\multicolumn{6}{c}{ Number of cells: 1135} \\
Application value(s) : 12 \\
Total no. of factors :
\end{tabular}

Figura 6. Frecuencias y porcentajes ofrecidos por el programa Goldvarb $X$.

\subsubsection{Interlocutores}

Para una lectura más clara de los datos, hemos organizado estos en una serie de tablas, que ofrecemos a continuación con los comentarios pertinentes.

9 En la introducción de datos en el programa hemos eliminado todas las ocurrencias que no se ajustaran a esas dos formas pronominales. En concreto, se han eliminado 239 (el 6,3\%), que recogían otras formas de tratamiento o que no contestaban, puesto que hay casos en que el interlocutor nunca se ha dirigido, por ejemplo, a un sacerdote o al servicio doméstico, o no tenían pareja, hijos, hermanos, etc. La inclusión de esta variante hubiera dado lugar a que el programa marcara con KnockOut estas situaciones, ya que se necesita alternancia de valores en cada una de las variables. Ello impediría seguir con los cálculos necesarios para realizar el análisis probabilístico. 
a) Ámbito I (la familia)

En el ámbito familiar (Tabla 2), vemos que predomina claramente el tuteo y, en algunos casos, como en el tratamiento a hijos, hermanos y pareja (con una sola excepción), el uso de tú es categórico. No ocurre lo mismo con la familia política, en donde alteran ambas formas, con un ligero predominio de usted. También se da esta circunstancia al dirigirse a los abuelos, que registran un alto porcentaje de usted, de acuerdo con la circunstancia general a tratar de esta forma a las personas mayores, a pesar de pertenecer a su entorno familiar.

\begin{tabular}{|c|l|c|c|c|c|}
\cline { 3 - 6 } \multicolumn{2}{c|}{} & \multicolumn{2}{c|}{ TÚ } & \multicolumn{2}{c|}{ USTED } \\
\cline { 3 - 6 } \multicolumn{2}{c|}{} & $\mathrm{N}^{\mathrm{o}}$ & $\%$ & $\mathrm{~N}^{\mathrm{O}}$ & $\%$ \\
\hline $\mathrm{a}$ & Padre & 93 & $83 \%$ & 19 & $17 \%$ \\
\hline $\mathrm{b}$ & Madre & 96 & $83,5 \%$ & 19 & $16,5 \%$ \\
\hline $\mathrm{c}$ & Hijos & 67 & $100 \%$ & 0 & $0 \%$ \\
\hline $\mathrm{d}$ & Hermanos & 110 & $100 \%$ & 0 & $0 \%$ \\
\hline e & Pareja & 107 & $99,1 \%$ & 1 & $0,9 \%$ \\
\hline $\mathrm{f}$ & Suegro & 45 & $47,9 \%$ & 49 & $52 \%$ \\
\hline g & Suegra & 44 & $46,3 \%$ & 51 & $53,7 \%$ \\
\hline h & Abuelo paterno & 62 & $61,4 \%$ & 39 & $38,6 \%$ \\
\hline i & Abuelo materno & 61 & $59,8 \%$ & 41 & $40,2 \%$ \\
\hline
\end{tabular}

Tabla 2. Frecuencias absolutas y relativas en el uso de tú y usted en el ámbito familiar.

b) Ámbito II (relaciones sociales)

En este ámbito, tú predomina claramente entre amigos (prácticamente categórico) y conocidos. Pero el grado de conocimiento, como se observa en la Tabla 3, es un factor determinante en la selección pronominal, ya que se pasa de un 77,5\% en el uso de $t u ́$ cuando la persona es conocida, a tan solo un 15,7 \% cuando es desconocida. Ya Almeida y Mendoza (1994:170), en su investigación realizada en San Sebastián de la Gomera, observaron que el factor más determinante en la selección pronominal es el grado de conocimiento de los interlocutores, y que cuando entre ellos existe mucho trato, la forma tú se vuelve casi categórica.

\begin{tabular}{|c|l|c|c|c|c|}
\cline { 3 - 6 } \multicolumn{2}{c|}{} & \multicolumn{2}{c|}{ TÚ } & \multicolumn{2}{c|}{ USTED } \\
\cline { 3 - 6 } \multicolumn{2}{c|}{} & $\mathrm{N}^{\mathrm{O}}$ & $\%$ & $\mathrm{~N}^{\circ}$ & $\%$ \\
\hline $\mathrm{j}$ & Amigos & 112 & $99,1 \%$ & 1 & $0,9 \%$ \\
\hline $\mathrm{k}$ & Vecinos & 66 & $57,4 \%$ & 49 & $42,6 \%$ \\
\hline 1 & Conocidos & 86 & $77,5 \%$ & 25 & $22,5 \%$ \\
\hline $\mathrm{m}$ & Desconocidos & 18 & $15,7 \%$ & 97 & $84,3 \%$ \\
\hline
\end{tabular}

Tabla 3. Frecuencias absolutas y relativas en el uso de tú y usted en el ámbito de las relaciones sociales. 


\section{c) Ámbito III (profesiones)}

En el ámbito profesional, usted sigue siendo mayoritario o, al menos, eso contestan los encuestados (Tabla 4). Se prefiere esa forma de tratamiento al dirigirse al médico, al profesor, al conductor del autobús y, en menor medida, al camarero, aunque aquí el factor conocimiento tenga un peso específico, debido a que, como se ha dicho anteriormente, el que responde al cuestionario suele tener un modelo de camarero o de conductor en la cabeza y es muy probable que, en este caso, el camarero sea una persona conocida porque se acuda siempre al mismo bar, lo que no ocurre con el conductor del autobús o el taxista. Hemos incluido aquí el tratamiento dispensado al sacerdote, pese a que muchos encuestados no contestan, al no ser creyentes o no frecuentar a este interlocutor. En el contexto académico, en nuestro estudio predomina claramente usted $(71,3 \%)$ sobre tú (28,7 \%), aunque esta cuestión es matizable. Ya Blas Arroyo (1998: 185) señalaba que el tuteo ganaba terreno cuando los alumnos pertenecían a grupos generacionales próximos al interlocutor (alumnos de doctorado cercanos a la edad del investigador) y era, en cambio, más variable en alumnos de primeros cursos de facultad. También Molina Martos (2005: 108) cree que la elección depende sobre todo de la edad de los profesores y del grado de intimidad que se tenga con ellos. No obstante, en su estudio se decantan claramente por el tratamiento formal, ya que responden que emplearían usted-sin tener en cuenta la edad o el grado de confianza- el $70 \%$ de las veces en el caso de las mujeres, y un $40 \%$ por parte de los hombres.

\begin{tabular}{|c|l|c|c|c|c|}
\cline { 3 - 6 } \multicolumn{2}{c|}{} & \multicolumn{2}{c|}{ TÚ } & \multicolumn{2}{c|}{ USTED } \\
\cline { 3 - 6 } \multicolumn{2}{c|}{} & $\mathrm{N}^{\mathrm{N}}$ & $\%$ & $\mathrm{~N}^{\mathrm{O}}$ & $\%$ \\
\hline $\mathrm{n}$ & Médico & 26 & $22,6 \%$ & 89 & $77,4 \%$ \\
\hline $\mathrm{o}$ & Profesor & 31 & $28,7 \%$ & 77 & $71,3 \%$ \\
\hline $\mathrm{p}$ & Jefe & 60 & $58,8 \%$ & 42 & $41,2 \%$ \\
\hline $\mathrm{q}$ & Sacerdote & 15 & $15,8 \%$ & 80 & $84,2 \%$ \\
\hline $\mathrm{r}$ & Servicio doméstico & 49 & $77,8 \%$ & 14 & $22,2 \%$ \\
\hline $\mathrm{s}$ & Camarero & 51 & $44,7 \%$ & 63 & $55,3 \%$ \\
\hline $\mathrm{t}$ & Conductor autobús/taxi & 29 & $25,2 \%$ & 86 & $74,8 \%$ \\
\hline
\end{tabular}

Tabla 4. Frecuencias absolutas y relativas en el uso de tú y usted en el ámbito de las profesiones.

d) Sexo y edad del interlocutor

Como vemos en la Tabla 5, la edad del interlocutor es un factor determinante a la hora de elegir el tratamiento. Si nos dirigimos a una persona mayor, optamos por usted, ya sea hombre o mujer nuestro interlocutor (más del $85 \%$ ). Si, en cambio, es de nuestra edad optamos por el tuteo. Este llega a ser casi general en el caso de que sea menor que nosotros $(95,7 \%)$. 


\begin{tabular}{|c|l|c|c|c|c|}
\cline { 3 - 6 } \multicolumn{2}{c|}{} & \multicolumn{2}{c|}{ TÚ } & \multicolumn{2}{c|}{ USTED } \\
\cline { 3 - 6 } \multicolumn{2}{c|}{} & $\mathrm{N}^{\mathrm{O}}$ & $\%$ & $\mathrm{~N}^{\circ}$ & $\%$ \\
\hline $\mathrm{u}$ & Hombre mayor que yo & 17 & $14,8 \%$ & 98 & $85,2 \%$ \\
\hline $\mathrm{v}$ & Hombre igual que yo & 103 & $89,6 \%$ & 12 & $10,4 \%$ \\
\hline $\mathrm{w}$ & Hombre menor que yo & 110 & $95,7 \%$ & 5 & $4,3 \%$ \\
\hline A & Mujer mayor que yo & 16 & $13,9 \%$ & 99 & $86,1 \%$ \\
\hline B & Mujer igual que yo & 103 & $89,6 \%$ & 12 & $10,4 \%$ \\
\hline C & Mujer menor que yo & 110 & $95,7 \%$ & 4 & $4,3 \%$ \\
\hline
\end{tabular}

Tabla 5. Frecuencias absolutas y relativas en el uso de tú y usted según la edad del interlocutor.

e) Sexo y estrato social del interlocutor

En cuanto al estrato social, ocurre algo similar a la edad, aunque en proporciones distintas (Tabla 6). Tendemos a tratar de usted a las personas que ocupan un orden jerárquico superior al nuestro $(70,2 \%)$ y a tratar de tú a los que son de igual o inferior estrato social (alrededor de un $80 \%$ ).

\begin{tabular}{|c|c|c|c|c|c|}
\hline & \multicolumn{2}{|c|}{ TÚ } & \multicolumn{2}{|c|}{ USTED } \\
\hline & & $\mathrm{N}^{\mathrm{o}}$ & $\%$ & $\mathrm{~N}^{\mathrm{o}}$ & $\%$ \\
\hline $\mathrm{x}$ & Hombre superior al mío & 33 & $28,9 \%$ & 80 & $70,2 \%$ \\
\hline $\mathrm{y}$ & Hombre igual al mío & 91 & $79,8 \%$ & 23 & $20,2 \%$ \\
\hline $\mathrm{z}$ & Hombre inferior al mío & 93 & $82,3 \%$ & 20 & $17,7 \%$ \\
\hline $\mathrm{D}$ & Mujer superior al mío & 34 & $29,8 \%$ & 80 & $70,2 \%$ \\
\hline $\mathrm{E}$ & Mujer igual al mío & 89 & $78,1 \%$ & 25 & $21,9 \%$ \\
\hline $\mathrm{F}$ & Mujer superior al mío & 91 & $80,5 \%$ & 22 & $19,5 \%$ \\
\hline
\end{tabular}

Tabla 6. Frecuencias absolutas y relativas en el uso de tú y usted según el sexo y el estrato social.

\subsubsection{Variables sociales}

a) Sexo del informante

En cuanto a las variables sociales, observamos que usted es más utilizado por las mujeres $(41,6 \%)$ que por los hombres $(33,8 \%)$, lo que indicaría, en principio, cierto conservadurismo por parte de ellas en la elección del tratamiento. Pero, como señala Calero (1993), el comportamiento de las mujeres depende mucho de factores contextuales, ya que, cuando pueden tutear, son las que más tutean $\mathrm{y}$, cuando se exige un tratamiento de respeto, son las que más utilizan usted, de ahí que, en términos generales, se obtengan los resultados observados en la Tabla 7. 


\begin{tabular}{|c|l|c|c|c|c|}
\cline { 2 - 5 } \multicolumn{2}{c|}{} & \multicolumn{2}{c|}{ TÚ } & \multicolumn{2}{c|}{ USTED } \\
\cline { 2 - 6 } \multicolumn{2}{c|}{} & $\mathrm{N}^{\mathrm{O}}$ & $\%$ & $\mathrm{~N}^{\mathrm{O}}$ & $\%$ \\
\hline 1 & Hombre & 1190 & $66,2 \%$ & 608 & $33,8 \%$ \\
\hline 2 & Mujer & 1026 & $58,4 \%$ & 732 & $41,6 \%$ \\
\hline
\end{tabular}

Tabla 7. Frecuencias absolutas y relativas en el uso de tú y usted según el sexo del informante.

b) Edad del informante

En cuanto a la edad, como ya se ha dicho, es, para la mayoría de los estudiosos, el factor fundamental para el análisis de la distribución sociolingüística de las formas de tratamiento. De esta manera, el avance de tú a expensas de usted se produce sobre todo en las generaciones más jóvenes, aunque haya autores (Calderón y Medina 2010: 203) que critiquen esta generalización, ya sea por la inestabilidad del habla juvenil, ya porque la mayor parte de las monografías existentes en España se fijan solo en las generaciones más jóvenes. En cualquier caso, en nuestro estudio observamos (Tabla 8) que las dos primeras franjas de edad (20-35 y 35-55 años) utilizan el tuteo en proporciones similares (66 \% y 64,7 \%, respectivamente), a una distancia considerable del sector de mayor edad (55,6\%). Esto puede suponer cierta ralentización en la extensión del tuteo, puesto que la generación intermedia, nacida en los años 60 y 70 del siglo XX, no se distancia apenas de los más jóvenes en el uso del tratamiento.

\begin{tabular}{|c|l|c|c|c|c|}
\cline { 3 - 6 } \multicolumn{2}{c|}{} & \multicolumn{2}{c|}{ TÚ } & \multicolumn{2}{c|}{ USTED } \\
\cline { 3 - 6 } \multicolumn{2}{c|}{} & $\mathrm{N}^{\mathrm{o}}$ & $\%$ & $\mathrm{~N}^{\circ}$ & $\%$ \\
\hline 1 & $20-34$ años & 777 & $66 \%$ & 400 & $34 \%$ \\
\hline 2 & $35-55$ años & 829 & $64,7 \%$ & 453 & $35,3 \%$ \\
\hline 3 & Mayor de 55 años & 610 & $55,6 \%$ & 487 & $44,4 \%$ \\
\hline
\end{tabular}

Tabla 8. Frecuencias absolutas y relativas en el uso de tú y usted según la edad del informante.

c) Estudios del informante

En cuanto a los estudios, buena parte de los trabajos que analizan esta variable coinciden en señalar que el empleo de usted es más común entre la población con menos nivel de estudios, mientras que el sector más instruido suelen recurrir con mayor frecuencia al tuteo. En nuestro trabajo (Tabla 9), observamos que el tuteo predomina en todos los sectores de la población, si bien los hablantes con estudios primarios utilizan más usted $(44,3 \%)$ que los de nivel más elevado (33, $8 \%$ ). La diferencia es bastante significativa (más de 10 puntos), lo que corroboraría la relación existente entre tratamiento y nivel cultural del hablante. 


\begin{tabular}{|c|l|c|c|c|c|}
\cline { 3 - 5 } \multicolumn{2}{c|}{} & \multicolumn{2}{c|}{ TÚ } & \multicolumn{2}{c|}{ USTED } \\
\cline { 3 - 6 } \multicolumn{2}{c|}{} & $\mathrm{N}^{\mathrm{o}}$ & $\%$ & $\mathrm{~N}^{\circ}$ & $\%$ \\
\hline 1 & Estudios primarios & 637 & $55,7 \%$ & 507 & $44,3 \%$ \\
\hline 2 & Estudios secundarios & 830 & $64,8 \%$ & 451 & $35,2 \%$ \\
\hline 3 & Estudios superiores & 749 & $66,2 \%$ & 382 & $33,8 \%$ \\
\hline
\end{tabular}

Tabla 9. Frecuencias absolutas y relativas en el uso de tú y usted según los estudios del informante.

d) Lengua habitual del informante

Por último (Tabla 10), no observamos grandes diferencias en la forma de tratamiento entre la población que tiene el valenciano como lengua habitual y los castellano-hablantes, si bien los primeros tienden a utilizar más el pronombre de respeto. Hay que advertir que en catalán, además de estas dos formas de tratamiento, existe también vós, que estaría a mitad camino entre vostè y tu. Vós, en palabras de Coromines (1971: 80) es un tramiento "cordial i decorós alhora" y es adecuado entre "persones d'igualtat perfecta pel que fa a la posició social, al sexe i adhuc a l'edat".

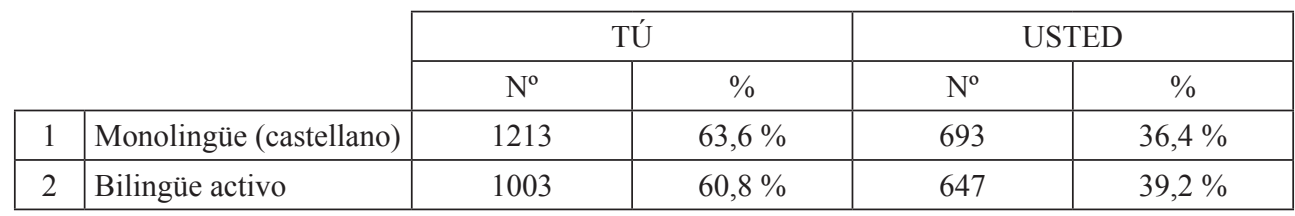

Tabla 10. Frecuencias absolutas y relativas en el uso de tú y usted según la lengua del informante.

\subsection{Estudio inferencial}

Además de los datos de frecuencia, el método variacionista busca crear un modelo teórico formado por un conjunto de probabilidades de que se dé un fenómeno cuando concurren diversas circunstancias. Los análisis de regla variable o análisis de regresión son los encargados de calcular las probabilidades de que aparezcan o no las distintas variantes en determinadas condiciones lingüísticas o sociales (Moreno Fernández 1994).

Por tanto, la importancia de este análisis reside en que permite conocer la probabilidad general de que aparezca uno de los factores (en el caso que estamos analizando, la presencia de tú o usted) cuando actúan simultáneamente todas las variantes de las variables o grupos de factores objeto de análisis.

En primer lugar, en el análisis de frecuencias hemos observado varios KnockOut, que aparecen porque el programa necesita que haya variación en todos los factores y, como se observa en la Figura 7, la presencia de tú es categórica en $c$ y $d$. 
$\begin{array}{cc}\text { Number of cells: } & 1135 \\ \text { Application value(s) : } & 12 \\ \text { Total no. of factors: } & 43\end{array}$

\begin{tabular}{|c|c|c|c|c|c|}
\hline \multicolumn{2}{|c|}{ Group } & 1 & 2 & Total & $\%$ \\
\hline 1 & (2) & 1 & 2 & & \\
\hline \multirow[t]{2}{*}{ a } & $\mathrm{N}$ & 93 & 19 & 112 & 3.1 \\
\hline & $\%$ & 83.0 & 17.0 & & \\
\hline \multirow[t]{2}{*}{$\mathrm{b}$} & $\mathrm{N}$ & 96 & 19 & 115 & 3.2 \\
\hline & $\%$ & 83.5 & 16.5 & & \\
\hline \multirow[t]{2}{*}{ C } & $\mathrm{N}$ & 67 & 0 & 67 & 1.9 \\
\hline & $\%$ & 100.0 & 0.0 & & * KnockOut * \\
\hline \multirow[t]{2}{*}{$d$} & $\mathrm{~N}$ & 110 & 0 & 110 & 3.1 \\
\hline & $\%$ & 100.0 & 0.0 & & * KnockOut * \\
\hline \multirow[t]{2}{*}{ e } & $\mathrm{N}$ & 107 & 1 & 108 & 3.0 \\
\hline & $\%$ & 99.1 & 0.9 & & \\
\hline
\end{tabular}

Figura 7. Presencia de KnockOut en el programa Goldvarb X.

Ello nos obliga a recodificar las variantes, puesto que en este punto el programa no nos permite continuar con el análisis de regresión. Así pues, podemos eliminar las variantes categóricas o recodificarlas. Hemos optado por esto último, ya que suprimirlas eliminaría del análisis dos variantes importantes para entender los resultados. En su lugar, hemos agrupado estos dos factores en $e$, que muestra resultados muy similares a los anteriores (Figura 8).

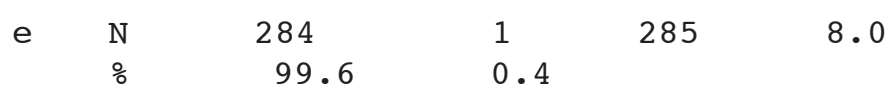

Figura 8. Recodificación de la variante $e$ en el programa Goldvarb X.

El programa Goldvarb $X$ cuenta con dos posibilidades de análisis probabilístico: Binominal 1 level y Binomial $U p$ \& Down ${ }^{10}$. El primero es más simple y es análogo al análisis de varianza (ANOVA), en cuanto a la información que aporta (Paolillo 2002: 79). En la Figura 9 reproducimos los resultados obtenidos de las formas de tratamiento cuando el valor de aplicación es el pronombre tú. La primera información de interés es el input (0.680), que nos da una frecuencia media de aparición del valor de aplicación de la

10 Para la explicación de los datos, hemos seguido las indicaciones de Moreno Fernández (1994), Paolillo (2002) y Tagliamonte (2006). 
variable dependiente. El valor 0.680 nos está indicando que hay una probabilidad del 68 $\%$ de que aparezca el pronombre tú en todos los casos, y, al ser superior a 0.5 , hay que entender que este factor se ve favorecido en las condiciones previstas. A continuación, en la primera columna, se nos da el efecto o peso (weight) de cada uno de los factores de cada grupo. Este conjunto de probabilidades constituye el modelo teórico creado a partir de los datos observados. Si la probabilidad es superior a 0.5 , nos está indicando que el factor explicativo favorece la variante explicada. En la columna App/Total se nos da información sobre los datos observados, dividiendo el número de casos de aparición del pronombre tú en cada factor partido por el número total de casos. En la última columna, Input \& Weight, se ofrecen unos valores en forma de probabilidad estimada, resultado de combinar el input y el peso. Lo mejor es que estos valores sean cercanos a los que encontramos en la columna anterior, puesto que si están muy alejados unos de otros podría indicarnos que no hay interacción entre los factores.

La adecuación entre el modelo teórico y los datos nos lo proporciona la función de verosimilitud ( $\log$ likelihood). Cuanto más alto sea este logaritmo, que aparece siempre en forma de número negativo, más verosímil resultará el modelo formado por las probabilidades. Al mismo tiempo que este cálculo, se realiza también la prueba del $j i$ cuadrado $\left(\chi^{2}\right)$, que determina la distancia existente entre los valores observados y los valores esperados según el modelo teórico. Mediante esta prueba del ji cuadrado podemos saber si los resultados se han dado o no por azar. Solo los valores cuyo nivel de significación estén por debajo de 0.05 señalan un rechazo de la hipótesis nula o de independencia y, por tanto, serán estadísticamente significativos.

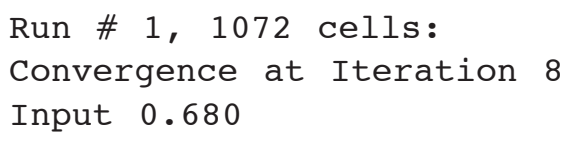




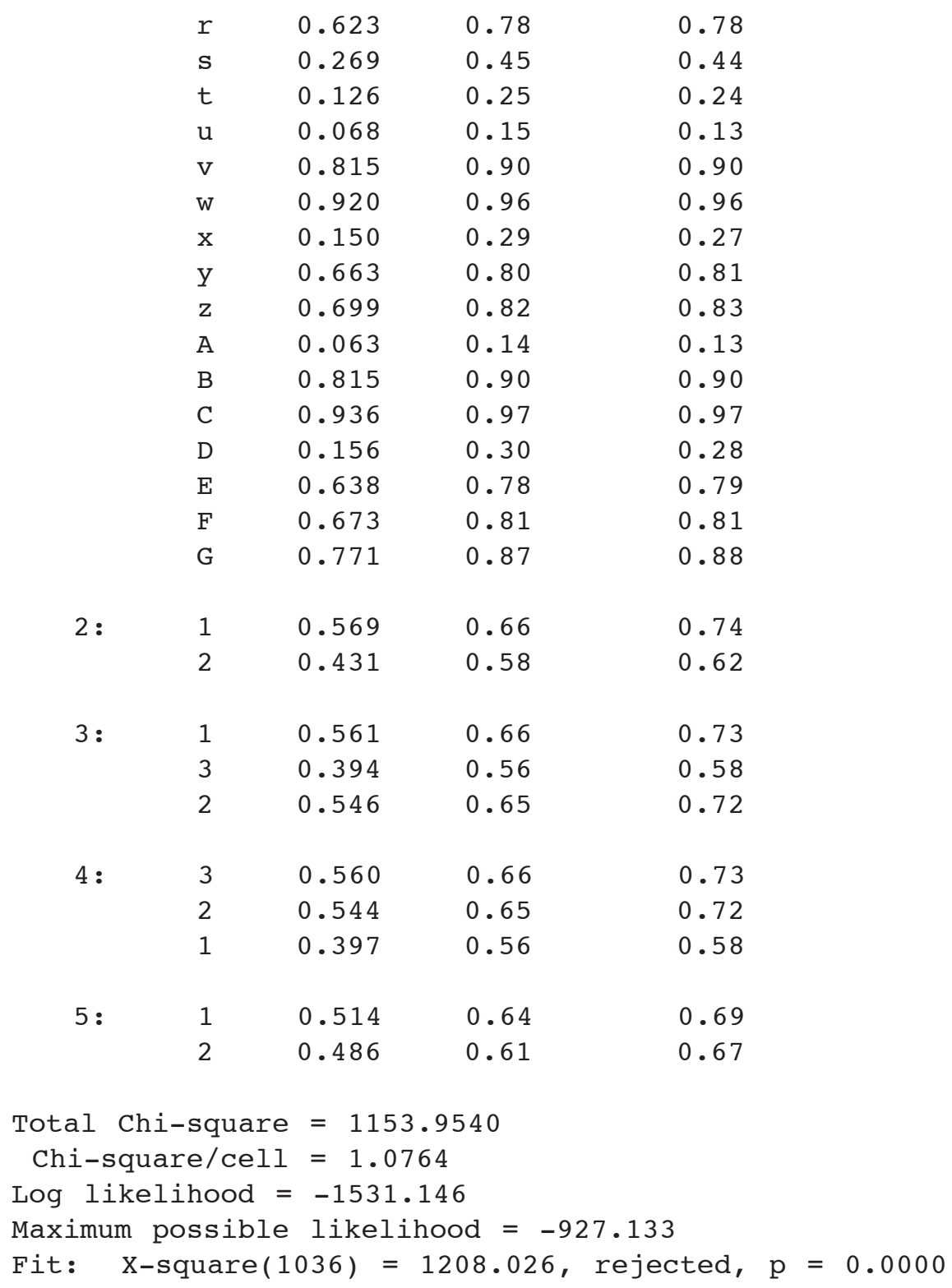

Figura 9. Datos estadísticos ofrecidos por el programa Goldvarb X.

El análisis de subida y bajada (Binomial Up \& Down), indica los pesos probabilísticos, ya vistos, y realiza distintos análisis o pasadas (runs) sobre los datos, seleccionando los grupos de factores estadísticamente significativos y descartando los que no lo son. Finalmente, indica los mejores análisis de subida y bajada (best stepping up run/best stepping down run), que deben manifestar los mismos resultados (Figura 10). 
All remaining groups significant

Groups eliminated while stepping down: 5

Best stepping up run: \#14

Best stepping down run: \#22

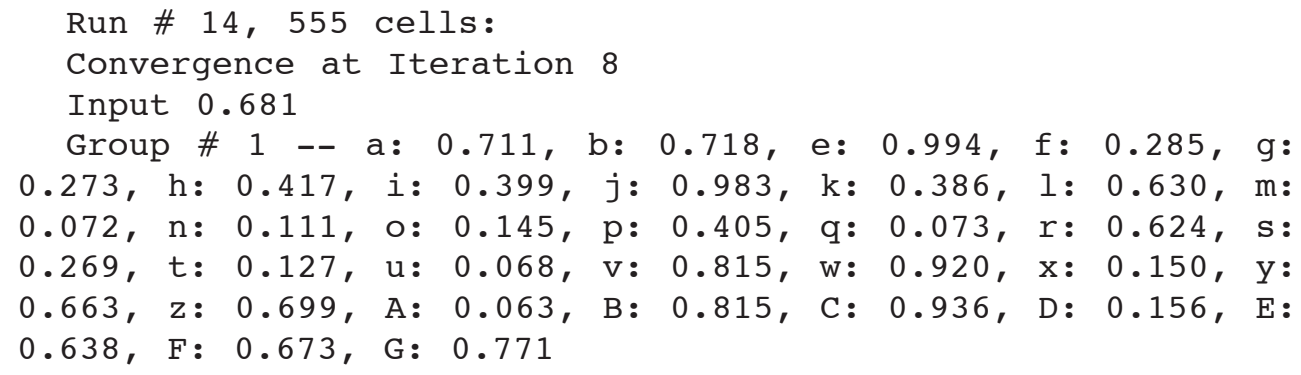

Figura 10. Análisis de subida y bajada (Binomial Up \& Down) en el programa Goldvarb $X$.

Analicemos con detalle los datos. Lo primero que llama la atención es la eliminación del Grupo 5 (lengua habitual) en los análisis de subida y bajada. Esto quiere decir que esta variable no resulta estadísticamente significativa con el valor aplicado. Como ya sabemos, los valores superiores a 0.500 favorecen la variante estudiada, en este caso la aparición del pronombre tú. En el grupo 1, que engloba todos los casos en que el hablante se dirige a un interlocutor, observamos que hay muchos factores por encima de este índice (Tabla 11). 


\begin{tabular}{|c|l|c|}
\hline a & Padre & 0.711 \\
\hline b & Madre & 0.718 \\
\hline e & Hijos / hermanos / pareja & 0.994 \\
\hline j & Amigos & 0.983 \\
\hline l & Conocidos & 0.630 \\
\hline r & Servicio doméstico & 0.624 \\
\hline v & Hombre igual que yo en edad & 0.815 \\
\hline w & Hombre menor que yo en edad & 0.920 \\
\hline y & Hombre de estatus igual al mío & 0.633 \\
\hline z & Hombre de estatus inferior al mío & 0.699 \\
\hline B & Mujer igual que yo en edad & 0.815 \\
\hline C & Mujer menor que yo en edad & 0.963 \\
\hline E & Mujer de estatus igual al mío & 0.638 \\
\hline F & Mujer de estatus inferior al mío & 0.673 \\
\hline G & Forma de tratamiento preferida & 0,771 \\
\hline
\end{tabular}

Tabla 11. Interlocutores que favorecen la variable tú.

Según estos datos, los interlocutores más próximos a $1, \mathrm{y}$, por tanto, los que más favorecerían el tuteo, serían los hijos, hermanos, pareja y amigos, por un lado, y aquellas personas que tienen menos edad que el interlocutor (sean hombres o mujeres). Por el contrario, los que están por debajo de 0.500 no favorecerían el tuteo (Tabla 12). Ni la familia política, ni los vecinos y desconocidos, ni las profesiones superan este umbral. De nuevo, llama la atención que la mayor edad del interlocutor vuelve a ser el factor más alejado de $1, \mathrm{y}$, por tanto, el que menos favorece el tuteo.

\begin{tabular}{|c|l|c|}
\hline f & Suegro & 0.285 \\
\hline g & Suegra & 0.273 \\
\hline h & Abuelo paterno & 0.417 \\
\hline i & Abuelo materno & 0.399 \\
\hline k & Vecinos & 0.386 \\
\hline m & Desconocidos & 0.072 \\
\hline n & Médico & 0.111 \\
\hline o & Profesor & 0.145 \\
\hline p & Jefe & 0.405 \\
\hline q & Sacerdote & 0.073 \\
\hline s & Camarero & 0.269 \\
\hline t & Conductor de taxi o autobús & 0.127 \\
\hline u & Hombre mayor que yo en edad & 0.068 \\
\hline$x$ & Hombre de estatus superior al mío & 0.150 \\
\hline A & Mujer mayor que yo & 0.063 \\
\hline D & Mujer de estrato superior al mío & 0.156 \\
\hline
\end{tabular}

Tabla 12. Interlocutores que no favorecen la variable tú. 
En relación con las variables sociales (Tabla 13), observamos que los varones $(0.569)$ están por encima de las mujeres (0.431), aunque hay que recordar que los valores próximos a 0.500 no promueven ni frenan el fenómeno. Lo mismo se puede decir de la edad, con dos grupos con valores próximos a 0.500: 20-34 años (0.563) y 35-55 años (0.545). Por debajo de 0.500 se encuentra el sector de la población mayor de 55 años $(0.394)$ que, consiguientemente, no favorece el fenómeno. Tampoco lo favorece el grupo con estudios primarios (0.395), mientras que los restantes están por encima, aunque muy próximos a 0.500: población con estudios secundarios (0.541) y universitarios (0.565). Por consiguiente, podemos decir que las variables sociales estudiadas no presentan mucha significación, aunque queda claro que no se ve favorecido el fenómeno del tuteo cuando el informante es persona mayor de 55 años o tiene estudios primarios.

\begin{tabular}{|l|l|l|}
\hline \multirow{3}{*}{ Sexo } & Hombres & 0.569 \\
\cline { 2 - 3 } & Mujeres & 0.431 \\
\hline \multirow{4}{*}{ Edad } & $20-35$ & 0.563 \\
\cline { 2 - 3 } & $35-55$ & 0.545 \\
\cline { 2 - 3 } & Mayor de 55 & 0.394 \\
\hline \multirow{3}{*}{ Nivel de estudios } & Primarios & 0.395 \\
\cline { 2 - 3 } & Secundarios & 0.541 \\
\cline { 2 - 3 } & Universitarios & 0.565 \\
\hline
\end{tabular}

Tabla 13. Valores estadísticos según las variables sociales de los informantes.

En cuanto al resto de índices estadísticos, vemos que el input, esto es, la frecuencia media de aparición del valor de aplicación de la variable dependiente (tú) es aquí de 0.681 , un valor relativamente alto y, en todo caso, superior a 0.500 , por lo que hay que entender que la aparición del pronombre de confianza se ve favorecida en las condiciones previstas. La función de verosimilitud ( $\log$ likelihood $=-1581.834$ ) indica la adecuación de la variante al modelo estadístico y su valor es siempre negativo. Cuanto menor sea la diferencia entre esta función y la máxima verosimilitud posible (Maximum possible likelihood $=-1213.126$ ), más se ajustará el modelo teórico a los datos analizados. Finalmente, la significación (significance) del logaritmo de la función de verosimilitud es inferior a $0.05(\mathrm{p}=0.000)$ en el análisis de subida, lo que revela la idoneidad del análisis. También queda rechazada la hipótesis nula o de independencia $(\mathrm{p}=0.0000)^{11}$.

\section{CONCLUSIONES}

Tanto los estudios dedicados al tema como la percepción social que se tiene de las formas de tratamiento, reflejada en artículos de prensa y anuncios publicitarios, ponen de manifiesto la extensión del tuteo en nuestra sociedad. Existe el convencimiento de que

11 La hipótesis nula o de independencia nos indica si los resultados se han dado o no por azar. Como ya se ha apuntado, solo los valores cuyo nivel de significación estén por debajo de 0.05 señalan un rechazo de dicha hipótesis. 
tú promueve relaciones más libres e igualitarias, propias de una sociedad que tiende a la pérdida de las distancias jerárquicas en las relaciones sociales. Además, se piensa que esta sociedad del conocimiento tiende a relaciones más horizontales y más de igualdad entre los sujetos que participan, y esto impone un trato más cercano. Pero hemos visto también que hay ciudadanos a los que no les gusta la extensión de ese trato igualitario y piensan que es conveniente mantener usted no solo en relaciones formales sino también en aquellas situaciones en donde se deba mantener una relación de jerarquía, haya una diferencia de edad o, simplemente, no exista ningún tipo de relación entre los interlocutores.

En el área estudiada, como muestra el análisis estadístico, el tuteo es mayoritario, y probablemente lo siga siendo, en las relaciones familiares (al menos, las más próximas) y con amigos y conocidos. Y es normal que así sea. También con aquellos que tienen una edad similar o menor a la del interlocutor, y con los que están por debajo en el estrato social, aunque en este caso también intervendrían otras variables, como el conocimiento y la confianza que se tenga con la persona, además de su edad.

Que ese tuteo se extienda al trato con el médico, el jefe, el camarero o el conductor del autobús ya tiene una probabilidad más baja. Primero, por la relación jerárquica que pueda existir, que supone una barrera, $\mathrm{y}$, después, por el grado de conocimiento o de vínculo que exista entre ellos, que hace que se pueda tutear a un camarero o a un médico en concreto, pero no a todos. Hoy se tutea más que hace unos años, es verdad, pero sigue existiendo un cierto "tratamiento cautelar", de primer acercamiento, que hace aflorar el usted.

La mayor barrera para la extensión del tuteo es la edad. Lo hemos visto en los análisis estadísticos. Las probabilidades de que aparezca la forma pronominal tú cuando nos dirigimos a personas de más edad son mínimas (0.068). También cuando hablamos con personas desconocidas (0.072).

Por otra parte, con relación a las variables sociales, los jóvenes son los que más tutean $y$, en consonancia con esta sociedad en la que priman sobre todo los valores de la juventud, se sigue tuteando hasta más allá de los 50 años. La brecha está en los mayores de 55, que marcan la frontera. Tal vez tienen más claro el tratamiento que deben dispensar porque no piensan solo en su propio sistema, sino también en el del receptor, y se sorprenden, en ocasiones, cuando alguien desconocido los tutea. También el sector con menos estudios es el que más se aleja del tuteo, según muestra el análisis estadístico. Es cierto que un nivel de estudios elevado suele llevar aparejado un mayor estatus, por lo que estaríamos ante el conocido eje de poder que condicionaría el tratamiento, según establecieron Brown y Gilman (1960): el que ocupa la posición de poder se dirige con un tú al subordinado, tal vez con menos estudios, que responde con usted. Aunque, de igual forma, podría pensarse que una diferencia de jerarquía no significa una relación de superioridad o inferioridad. Se preserva el usted como una simple jerarquía laboral, sin más consideraciones. Con relación al sexo no se observan grandes diferencias entre hombres y mujeres, aunque ellas utilizan más el pronombre de respeto. No obstante, como se ha apuntado en el trabajo, esta variable ha de ser puesta en relación con otras, puesto que aquí el uso de tú o usted va a depender mucho de los factores contextuales. Por último, en referencia a la lengua habitual de comunicación, hemos visto que esta variable no resulta estadísticamente significativa y, por tanto, ha quedado descartada en el análisis. Por otra parte, son pocos los estudios que ponen en relación ambas variables en territorios bilingües. Para el caso del vasco, Blas Arroyo (2005: 302) afirma que en este territorio el avance de tú se ha disparado en las dos últimas décadas en 
una proporción muy superior a la que todavía puede observarse en otras regiones de España. Para Sampedro Mella (2015: 340), que estudió las formas de tratamiento en el español de Galicia, la lengua gallega no parece ser un factor determinante, ya que concluye que los factores más importantes en la selección del pronombre tienen que ver con la edad de los interlocutores y, en algunos casos, con la formalidad de la situación comunicativa.

\section{Referencias bibliográficas}

Alba de Diego, V. y J. Sánchez Lobato (1980). “Tratamiento y juventud en la lengua hablada. Aspectos sociolingüísticos”, Boletín de la Real Academia Española, 60, pp. 95-130.

Almeida, M. y J. Rodríguez Mendoza (1994). "Formas de tratamiento en español actual”. En Strolidi, J. (ed.). Recherches en linguistique hispanique, Actes du colloque d'Aix-en-Provence. Aix-enProvence: Université de Provence, pp.167-178.

Blas Arroyo, J.L. (1998). "Una variable sociopragmática: la alternancia tú/usted”. En Blas Arroyo, J.L. Las comunidades de habla bilingües. Pórtico: Zaragoza, pp. 167-189.

Blas Arroyo, J.L. (2005). Sociolingüística del español. Desarrollos y perspectivas en el estudio de la lengua española. Madrid: Cátedra.

Borrego Nieto, J., J.J. Gómez Asencio, y J.A. Pérez Bowie (1978). "Sobre el tú y el usted”, Studia Philologia Salmanticensia, 3, pp. 53-70.

Brown, R. y A. Gilman (1960). "The Pronouns of Power and Solidarity". En Sebeok. T.A. Style in Language. Massachusetts: MIT Press, pp. 253-276.

Brown, P. y S.C. Levinson (1987). Politness. Some universals in language use, Cammbridge: C.U.P.

Buzón García, J. (2013). La expresión de la futuridad en el español de Valencia. Estudio sociolingüístico, Valencia: Universitat de València. Tesis doctoral: http://roderic.uv.es/handle/10550/28499 (10-82017).

Calderón Campos, M. y F. Medina Morales (2010). "Historia y situación actual de los pronombres de tratamiento en el español peninsular”. En Hummel, M., B. Kluge y M. E. Vázquez Laslop (eds.), pp. 197-222.

Calero, M.Á. (1993): "Reseña al libro de Medina López, J. Sociolingüística del tratamiento en una comunidad rural (Buenavista del Norte, Tenerife)", Lingüística, Año 5, pp. 179-195.

Casanova, E. (2003). "La situación lingüística en la Comunidad Valenciana: el valenciano, caracterización y justificación”. En Ridruejo, E. (coord.). Las otras lenguas de España. Publicaciones de la Universidad de Valladolid, pp. 117-163.

Cestero, A.M. (2013). "El proyecto para el estudio sociolingüístico del español de España y América (PRESEEA)", Español Actual, 98, pp. 227-234.

Coromines, J. (1971). Lleures i converses d'un filòleg. Barcelona: Club editor.

Fernández, F. y K. Gerhalter (2017). "Pronombres de segunda persona y fórmulas de tratamiento en español: una nueva bibliografía", LinRed, 14: http://www.linred.es/informacion_pdf/LR_ informacion20_20170219.pdf (1 de agosto de 2017).

Fontanella de Weinberg, B. (1999). "Sistemas pronominales de tratamiento usados en el mundo hispánico”. En Bosque, I. y V. Demonte (dirs.). Gramática descriptiva de la lengua española. Madrid: Espasa, vol. I, pp. 1399-1425.

Hummel, M., B. Kluge y M. E. Vázquez Laslop (eds.). Formas y fórmulas de tratamiento en el mundo hispánico. México: El Colegio de México/Karl-Franzens Universität Graz.

Iglesias Recuero, S. (2001). "Los estudios de la cortesía en el mundo hispánico. Estado de la cuestión", Oralia, 4, pp. 245-298.

Jordá, R.M. (1986). La industria en el desarrollo del Área Metropolitana. Valencia: Institució Valenciana d'Estudis i Investigació.

Labov, W. (2004). Principios del cambio lingüístico. II. Madrid: Gredos. 
Michele de Oliveira, S. (2010). "La integración de la teoría y la metodología como desencadenante de un nuevo modelo de formas y fórmulas de tratamiento". En M. Hummel, B. Kluge y M. E. Vázquez Laslop (eds.), pp. 59-77.

Molina Martos, I. (1993). "Las fórmulas de tratamiento de los jóvenes madrileños. Estudio sociolingüístico", Lingüística Española Actual, XV/2, pp. 249-263.

Molina Martos, I. (2005): "Evolución de las fórmulas de tratamiento en la juventud madrileña a lo largo del siglo XX: un estudio en tiempo real”. En Rodríguez, F., F.M. Casado y N. Catalá. El lenguaje de los jóvenes. Barcelona: Ariel, pp. 97-116.

Moreno Fernández, F. (1994). "Status quaestionis: sociolingüística, estadística e informática", Lingüística, 6, pp. 95-154.

Moreno Fernández, F. (1996). "Metodología del Proyecto para el Estudio Sociolingüístico del Español de España y de América (PRESEEA)”, Lingüística, 8, pp. 257-287.

Moreno Fernández, F. (2005). "Corpus para el estudio del español en su variación geográfica y social. El corpus PRESEEA”, Oralia, 8, pp. 123-139.

Paolillo, J. C. (2002). Analyzing Linguistic Variation: Statistical Models and Methods. Stanford: Center for the Study of Language and Information Publications.

Paredes, F. (2010). “¿Es factible un cuestionario estándar para el estudio del tratamiento? La experiencia del proyecto PRESEEA en Madrid y Alcalá de Henares” En Hummel, M., B. Kluge y M. E. Vázquez Laslop (eds.), pp. 165-195.

Roselló Verdeguer, J. (2013). "Las formas de tratamiento". En Gómez Molina, J.R. El español de Valencia. Estudio sociolingüistico. Berna: Peter Lang.

Sampedro Mella, M. (2015). "Las formas de tratamiento en un corpus de entrevistas semidirigidas de español de Galicia”, ELUA, 29, pp. 319-344.

Sankoff, D., S.A. Tagliamonte y E. Smith (2005). Goldvarb X: A Variable Rule Application for Macintosh and Windows. Toronto: University of Toronto: http://individual.utoronto.ca/tagliamonte/ goldvarb.html [10-9-2017].

Soler-Espiauba, D. (1994). “¿Tú o usted? ¿Cuándo y por qué? Descodificación al uso del estudiante de español como lengua extranjera", Actas del V Congreso Internacional de ASELE, pp. 199-208.

Tagliamonte, S.A. (2006). Analysing Sociolinguistic Variation. Cambridge, UK: Cambridge University Press. 